\title{
Professional Disruption in Health Regulation Electronic Cigarettes in the European Union
}

\author{
Hasselbalch, Jacob
}

Document Version

Accepted author manuscript

Published in:

Journal of Professions and Organization

DOI:

10.1093/jpo/jov009

Publication date:

2016

License

Unspecified

Citation for published version (APA):

Hasselbalch, J. (2016). Professional Disruption in Health Regulation: Electronic Cigarettes in the European

Union. Journal of Professions and Organization, 3(1), 62-85. https://doi.org/10.1093/jpo/jov009

Link to publication in CBS Research Portal

\section{General rights}

Copyright and moral rights for the publications made accessible in the public portal are retained by the authors and/or other copyright owners and it is a condition of accessing publications that users recognise and abide by the legal requirements associated with these rights.

Take down policy

If you believe that this document breaches copyright please contact us (research.lib@cbs.dk) providing details, and we will remove access to the work immediately and investigate your claim. 


\section{Professional Disruption in Health Regulation: Electronic Cigarettes in the European Union}

\section{Jacob Hasselbalch}

Journal article (Accepted manuscript*)

\section{Please cite this article as:}

Hasselbalch, J. (२०16). Professional Disruption in Health Regulation: Electronic Cigarettes in the European Union. Journal of Professions and Organization, 3(1), 62-85. 001: 10.1093/jpo/jov009

This is a pre-copyedited, author-produced version of an article accepted for publication in Journal of Professions and Organization following peer review. The version of record is available online at:

DOl: dx.doi.org/10.1093/jpo/jov009

* This version of the article has been accepted for publication and undergone full peer review but has not been through the copyediting, typesetting, pagination and proofreading process, which may lead to differences between this version and the publisher's final version AKA Version of Record.

Uploaded to CBS Research Portal: February २०1९ 


\begin{abstract}
:
How do professions respond to fast-moving technological changes? Disruptive innovations overturn expectations about how markets function and develop, and they often raise moral, legal and scientific concerns among professionals. Sudden technological changes can result in a state of professional disruption, in which technological change challenges the institutional arrangements of a profession. This article distinguishes between fast and slow processes of professional change, focusing on the role of technology as one cause of fast changes to a profession. Professionals and non-professionals engage in framing contests that draw on cognitive, normative and relational keys to signal their expectations. It is in these framing contests that professionals run the risk of disruption. Drawing on interview data with key policy actors, I investigate electronic cigarettes regulation in the European Union and its recent revision to the Tobacco Products Directive. Medical and public health professionals that control tobacco issues were challenged by a coalition of e-cigarette industry representatives, e-cigarette users, and liberal politicians. The challengers drew on the contending norm of harm reduction in tobacco control, which successfully challenged the centrality of the abstinence norm in the institutional arrangements of the medical and public health professions and their organizational field. By discussing the parallels to other related cases in health regulation, I draw out the implications of the study for researchers and policymakers.
\end{abstract}

\title{
KEY WORDS
}

Professional disruption, technology, organizational fields, institutional work, health regulation, electronic cigarettes 


\section{INTRODUCTION}

The professions are the 'preeminent institutional agents of our time' (Scott 2008 p. 219). More so than any other identifiable group of actors, professionals are calling the shots when it comes to the creation, maintenance and disruption of the institutions of modern societies (Brint 1994). They are the people doing the 'institutional work' (Lawrence \& Suddaby 2006) that modern societies depend upon. A good measure of that work has to do with the institutions that regulate the market economy. The professions have been identified as gatekeepers ensuring the integrity and functionality of societal and economic institutions such as capital markets and corporate governance (Coffee 2006). What happens when the markets that such professionals are involved in suddenly and unexpectedly change, for example following the introduction of new technologies into the market? If the professionals are 'the lords of the dance' of political economic transformations (Scott 2008), will they have to adapt to the beat of a faster-moving market? This paper argues that sudden technological changes can result in a state of professional disruption, in which technological change disrupts the institutional arrangements of a profession. This claim will be substantiated through the analysis of electronic cigarette (e-cigarette) regulation in the European Union (EU), and especially the disruptive potential of e-cigarettes towards the organizational field of tobacco control, within which medical and public health professionals play a central role.

E-cigarettes is an interesting case to study when investigating professional disruption. E-cigarettes are a disruptive innovation (Bower \& Christensen 1995; Christensen \& Raynor 2003; Christensen 1997) in the sense that they have grown rapidly to become an estimated USD 3 billion market today with high rates of projected future growth, overturned expectations about the future of the tobacco market, and raised a number of questions about their legal status (World Health Organization 2014). When e-cigarettes made their entrance, the question that regulators were forced to consider was whether they fit into existing tobacco 
product regulation, or whether they should be treated as medicines or consumer products. Ecigarettes were challenging since they seemed to slip between the gaps of the different regulatory regimes (World Health Organization 2010 p. 30). Where to place them depends on a number of considerations, but within the tobacco control ecology that was called on to advise regulators it depends on whether you view e-cigarettes as a legitimate pathway to the reduction of tobacco smoking or as products that could potentially undermine years of efforts to 'denormalize' smoking.

There is therefore a schism within the tobacco control ecology that has grown over time and been especially exacerbated by the question of how to relate to e-cigarettes. This is best captured by tracing the World Health Organization's (WHO) evolving position on the matter over time. In 2008, the WHO's position is very clear: "Contrary to what some marketers of the electronic cigarette imply in their advertisements, the WHO does not consider it to be a legitimate therapy for smokers trying to quit" (World Health Organization 2008a). In a WHO podcast one week after the press release, Dr. Douglas Bettcher from the WHO Tobacco Free Initiative explains the reasoning behind their stance: "The WHO knows of absolutely no scientific evidence whatsoever that would confirm that the electronic cigarette is a safe and effective smoking cessation device. Toxicological tests and clinical trials have not been performed on this product and the number of chemical additives in the product, which could be very toxic, has not yet been confirmed" (World Health Organization 2008b). This was followed by a report in 2009 on the scientific basis for e-cigarette regulation, which asserted that e-cigarettes "pose significant public health issues" and threaten to "undermine smoking cessation efforts by proposing unproven devices for smoking cessation in the place of products of proven efficacy" (World Health Organization 2009 p. 3). The report goes on to recommend that e-cigarettes be regulated as combination drugs and medical devices and not as tobacco products. A 2010 WHO Drug Information article shows no sign of a shift in 
opinion - indeed, there are direct repetitions in the article of statements from the earlier publications (World Health Organization 2010). However, once we get to 2014, the picture has changed:

ENDS [electronic nicotine delivery systems, or e-cigarettes] are the subject of a public health dispute among bona fide tobacco-control advocates that has become more divisive as their use has increased. Whereas some experts welcome ENDS as a pathway to the reduction of tobacco smoking, others characterize them as products that could undermine efforts to denormalize tobacco use. ENDS, therefore, represent an evolving frontier, filled with promise and threat for tobacco control. Whether ENDS fulfil the promise or the threat depends on a complex and dynamic interplay among the industries marketing ENDS (independent makers and tobacco companies), consumers, regulators, policy-makers, practitioners, scientists, and advocates. The evidence and recommendations presented in this report are therefore subject to rapid change. (World Health Organization 2014 pp. 1-

Compared with earlier statements, the unmitigated warnings have given way to divided opinions, the co-production of knowledge with various stakeholders has taken the place of the calls for more scientific evidence, and rapid change is taken as a given. The shift of opinion within the WHO reflects the professional disruption to the tobacco control ecology, experienced in many different regulatory settings of which the EU was just one. This paper focuses on the 'complex and dynamic interplay' in the case of the EU's efforts to regulate ecigarettes. In the 2012 revision of the Tobacco Products Directive (TPD), the issue of how to regulate e-cigarettes quickly became the most contentious issue in the Directive and threatened to halt negotiations completely. The TPD negotiations provide an ideal setting for 
studying this complex and dynamic interplay between the medical and health professionals, the wider e-cigarette ecology and European regulators as they came to a head over the definitional and scientific questions that drove the debate. In the course of the policy debate, new actors and new frames of understanding were introduced that challenged the jurisdiction and norms of the tobacco control ecology and resulted in a professional disruption.

There are good reasons to expect professional disruption to show up in regulatory debates over new technologies. Technologies are co-constituted by their economic, social and political environments (Latour 1993), and this also holds true for the growth of medical knowledge, which "depends on patterns of coordination across complementary dimensions like scientific research, communities of practitioners, regulation, delivery of patient care and the market process" (Consoli \& Ramlogan 2008 p. 32). To study the disruptive potential of ecigarettes on the tobacco control ecology, it is therefore important to consider the wider set of actors and organizations that have a stake in defining the future of e-cigarettes.

The professions play an important role in regulatory debates: they can be seen as a 'third logic' operating between the state and the market (Freidson 2001) - a third ideal type of organizing work in addition to markets and hierarchies. Perhaps most crucially, the question of how new technologies are to be institutionalized through regulation, for example, requires institutional work to be undertaken by professionals, who possess the required expertise and status to lay claim to these jurisdictions and provide the needed policy inputs. In the revision of the TPD, the EU institutions consulted frequently with medical and public health professionals from the tobacco control ecology. During the course of the negotiations, the medicinal products framing favoured by the tobacco control ecology encountered massive resistance from the community of e-cigarette users (the 'vaping community') who entered into an alliance with the e-cigarette industry and liberal politicians who favoured a harm reduction approach to tobacco control instead of the mainstream abstinence agenda. As a 
consequence of the regulatory debate and compromise outcome, the harm reduction norm gained momentum within the tobacco control ecology and challenged the centrality of the abstinence norm, thereby exacerbating the internal division between its professional members. The system of professions and how they interact with non-professional groups is hence key to figuring out how the institutions of the market society get negotiated (Brint 1994; Coffee 2006; Muzio et al. 2013; Scott 2008). What is surprising about the present study is that it suggests that professionals can contribute to undermining their own profession when such institutional work results in unexpected feedback effects that lead to professional disruption. ${ }^{1}$

The paper proceeds as follows: first, the theory section begins by making a distinction between fast and slow processes of professional change, and it considers how to think about technological change in this context. Following this, I briefly discuss the data and methods on which the study is based. Thereafter, I illustrate the argument by drawing on a case study of electronic cigarette regulation in the European Union. This is followed by a discussion on the dynamics of professional disruption in a few similar cases to display other sides of the issue as well as its general tendencies.

\section{THEORY}

In clarifying the theoretical contribution that the paper seeks to make, it is helpful to distinguish between slow and fast processes of professional change. We know much about the slow processes, but little about the fast processes. Professional disruption, the analytical focus of the paper, is one example of a fast process, but it is not the only one.

\footnotetext{
1 The paper makes the analytical distinction between professionals meaning the agents and the profession meaning the institution.
} 


\section{Slow processes of professional change}

The slow processes of professional change chart the evolution of the system of professions over long time spans. Early work on the sociology of professions focused on the competition between the professions to establish jurisdictional borders and control work (Abbott 1988; Larson 1977). Analyses emphasized the emergence of professional associations and the resulting system of professions. Professional claims for legitimate control are judged by various 'audiences' in the wider social system, such as the state, the public, universities, competitors and co-workers. Professionals and non-professionals engage in complex interactions and struggles to 'pitch' their claims to audience members, which legitimates their jurisdictions. These interactions are often characterized by strategies that seek to establish alliances between professional groups and other ecologies, specifically by identifying 'hinges' that provide different rewards in their respective ecologies or by institutionalizing a copy or colony of one ecology in another (Abbott 2005). Studying the ebb and flow of such links between various actors over time has proven to be a fruitful way to analyse the slowmoving processes of professional change, such as Abbott (2005) does when looking at medical licensing regimes in $19^{\text {th }}$ century New York and England. More generally, this suggests that the slow processes of professional change thus have to do with longer-running co-constitutive effects between the institutions of the state, the market and the professions.

There are several examples of professions being invoked to explain how they coconstitute states on the one hand and markets on the other. On the state-professions side, Abbott (1988) highlights the role of the state in granting and protecting through law the jurisdictions of lawyers and doctors; Cooper \& Robson (2006) demonstrate the growing importance of accounting firms in supporting the regulatory processes of the state; and Johnson (1972) has shown how accounting professionals supported the expansion of the British Empire into new colonies. On the market-professions side, Mennicken (2010) charts 
the co-evolution of auditing and marketization in post-Soviet Russia; Fourcade \& Khurana (2013) reveal a similar process driving changes in business education and markets in the U.S.; and Lebaron (2001) discusses the central role played by economists in constructing and facing the crisis in France in December 1995. The idea of yoking together professions and institutions is not new: Dimaggio (1991) has suggested that the co-evolution of professions and the state may be considered one of the primary engines of institutional change. More recently, Suddaby \& Viale (2011) describe the professional project as an endogenous mechanism of institutional change, leading to recent work towards developing an institutionalist sociology of the professions (Muzio et al. 2013).

An important side to this story is the recent attention to how professional work increasingly transcends the boundaries of the nation-state and domestic markets, leading to calls for a transnational sociology of the professions (Faulconbridge \& Muzio 2012). Thus, the professions are now seen as central to explaining a range of issues in global governance and international political economy, such as: capital account liberalization in emerging markets (Chwieroth 2007), knowledge networks in the World Bank (Stone 2013), financial reform (Seabrooke \& Tsingou 2014), and demographic change (Seabrooke \& Tsingou 2015). This trend speaks to the centrality of professions and professionals in organizing various aspects of modern societies, even in areas where nation-states and domestic markets - the traditional domains of the professions - cannot reach. Thus, it suggests that the professions and the increasingly large and global organizations in which they reside are not only being affected by globalization, but are also helping to drive it (Suddaby et al. 2007). However, it also suggests that the system of professions is itself changing as a consequence of the role it plays in driving globalization. For example, recent work has started to question whether the hard line between professionalized and other workers has much analytical value in contemporary organizational settings, given 'the rise over the last few decades of a number of 
very successful knowledge-intensive occupations, such as management consultancy, IT/systems analysis, advertising, financial intermediaries, and so on, which have not adopted traditional professionalization strategies' (Brock et al. 2014 p. 8). Modern societies have increased the knowledge intensity and marketization of work, while also changing the character of the organizations that make up professional workplaces (Faulconbridge \& Muzio 2012; Noordegraaf 2007 pp. 762-764).

As work specialization increases, there are growing cadres of workers under pressure to professionalize. At the same time, knowledge societies are becoming increasingly resistant to professionalization: 'they resist clear definitions of the word professional, they resist clear standards and measures of success, and they resist the rise of 'thick' institutions such as strong professional communities' (Noordegraaf 2007 p. 763). This brings the modern organization of work into an inherent instability, leading some to argue that a shift of focus is required from professions to professionalism (Evetts 2003), and that 'pure professionalism' has given way to more hybrid forms of professionalism (Noordegraaf 2007) and led to new types of professionals such as 'issue professionals' (Henriksen \& Seabrooke 2015). The upshot of this debate is that while strongly defined professions are not as ubiquitous as traditional models of the professions might have foreseen, it does not change the fact that jurisdictional struggles are still waged between any groups that can lay claim to expertise (Eyal 2013).

On one level, the sociology of professions does already have the tools at its disposal to successfully analyse longer-term shifts of professionalization and professional work. On a different level, considering the body of literature reviewed here in brief, the discipline also tells a story about the evolution of professions and their changing role in society over time. The professions and professionals thus seem to be key actors when it comes to explaining the expansion of states, markets and organizations, especially as they move into the transnational 
domain - and this very same expansion is now exerting new pressures on the system of professions. There is good reason to see them as the 'lords of the dance' as proposed by Scott (2008), choreographing the transformations of political economic systems. By definition, any such transformation is dependent on the creation of new institutions and the disruption of old ones. There is no 'dance' without 'institutional work', that is, the 'purposive action of individuals and organizations aimed at creating, maintaining and disrupting institutions' (Lawrence \& Suddaby 2006 p. 215). If the dance in its entirety refers to the slow moving processes of professional change, then the fast moving processes are the individual steps of the dance, the individual examples of institutional work. In other words, the fast moving processes zoom in on the individual jolts of change that, when zoomed out on and put in sequence, allow the slower moving processes to unfold. Abbott (2001a p. 257) puts it in different terms: 'minor structures' and 'master structures'. Some patterns of relations are connected to other patterns of relations, more so than others. These are master structures, which consequently have a longer duration in time. They are overarching settlements of many minor structures. When the minor structures align in a certain way, they allow master structures to be challenged and possibly overturned. Studying individual instances of disruptive innovation and how they affect professional groups requires us to zoom in on the minor structures and the fast-moving processes.

\section{Fast processes of professional change}

There are many ways that we might expect the nature of the professions and professional work to rapidly change - technology is just one vector of change. Other examples could be sudden social unrest, revolution or war, disasters or crises both natural and manmade, changes in the political ecology and regimes that govern the professions, and so on. I restrict myself to the role of technological change in this section. 
Whereas slow processes of professional change unfold gradually over time and encompass several events, stages and trends, fast processes unfold through the course of a single, disruptive event. It is useful to make a parallel to studies on changes in organizational fields to understand the distinction. The concept of organizational fields connotes 'the existence of a community of organizations that partakes of a common meaning system and whose participants interact more frequently and fatefully with one another than those actors outside the field' (Scott 1995 p. 56). Studies on how organizational fields change over time have recognized the importance of the disruptive event as an external trigger that sets off rapid processes of change in the field (Hoffman 1999; Reay \& Hinings 2005; Wooten \& Hoffman 2008). Most of these studies look at the consequences of disruptive events at different points in time in the evolution of an organizational field, stressing how they mark the transition points between different stages of the field. New stages are marked by new institutional and organizational arrangements. They thereby treat disruptive events as exogenous variables that explain why change happens at certain points in time. This treatment of disruptive events lacks an endogenous account of how the social processes unfold during the course of a single disruptive event and how these processes co-constitute the disruption. I want to bring attention to how single disruptive events are made sense of and navigated through by professionals in organizational fields. This requires that we focus analytical attention on shorter time spans and on the moves made by individual actors as they shape the contours of the disruptive event.

Disruptive events precipitate change by creating uncertainty leading to unorthodox experiments and by restructuring fields through the relocation of boundaries and bases of competition (Hoffman 1999 p. 353). In other words, they exhibit both material and immaterial characteristics: there are objective material changes to some aspect of the world which professionals are concerned with, but what these changes mean and entail is uncertain 
and open to interpretation and contestation. When it comes to disruptive events that involve technological change, two seminal treatments in neo-institutional theory are relevant to consider, and they shed light on the material and immaterial dimensions respectively. Leblebici et al. (1991 p. 338) define technology as those 'tools, knowledge, and methods that endow capabilities to agents in a field for establishing and maintaining their transactions'. It 'is cumulative and expands the potential actions of participants'. Meanwhile, Munir \& Phillips (2005 pp. 1665-1669) consider technological innovation as an external 'trigger' for institutional change brought about by the discursive strategies of actors to transform the meaning the technology embodies. Technological change therefore plays a dual role, simultaneously material and immaterial. Materially, it enables new practices. Immaterially, it opens a discursive space that actors compete to fill with contending meanings. Both are equally valid pathways to institutional change and are indeed frequently concurrent. However, the technological innovation as 'trigger' metaphor requires a closer look - triggers represent exogenous phenomena that instigate change from outside a social situation, but the purpose here is to supply an endogenous account.

Technologies enter organizational fields not as events or triggers, but as 'turning points' (Abbott 2001a). With any given technology, it is difficult to point at a precise point in time at which it can be said that the technology was invented or made a decisive impact. Abbott (2001b) demonstrates this with the example of the invention of the grenade harpoon. While the invention of the grenade harpoon is credited to Svend Foyn's 1870 patent, this obscures the presence at the time of many contending designs of grenade harpoons from other inventors that were experimented with and put to use in all parts of the whaling industry. To say that the grenade harpoon was invented by this person on this date is more of a 'historical fact' (Carr 1961) than a reflection of the lived experience of $19^{\text {th }}$ century whalers. The diffusion of inventions and innovations are processes with temporal durations that play out in 
social interaction (Rogers 2003; Wejnert 2002) - it does not make sociological sense to equate inventions with events. Rather, there are periods in which multiple processes, actors and framings of the technology compete for recognition. They build on each other and interrelate in non-linear ways. A more fitting description of these turbulent periods comes in the form of Abbott's 'turning points'. Rather than think about technological change as a discrete, abrupt event that is exogenous to the social process, turning points consider the convergence of simultaneously running endogenous social processes that align just so, 'like the tumblers of a lock' (p. 256), to allow previously stable conditions to be overturned. This emphasis on the social context of invention and innovation is also more in line with the everyday practices of scientific work (Latour 1987).

When new technologies enter organizational fields they lead to a state of 'punctuated cooperation' (Vollmer 2013). The technological state of a social system imparts a set of shared expectations onto the actors about the capabilities and future development of that system. Disruption occurs when some actors call attention to how a new technology brings about or threatens material changes in the system. Vollmer (2013 pp. 38-47, 136-7) refers to this as 'marking disruptiveness', drawing attention to how disruptive events are first and foremost socially constructed (see also Hoffman 1999 p. 366). For the marking of disruptiveness to be credible, it helps if there already are specific material changes that actors can indicate or if there are believable narratives available that tell how such changes may come about. Nonetheless, the marking of disruptiveness is a discursive action, and this is what brings about a state of punctuated cooperation 'in which participants lose a previously established level of cooperation in maintaining expectations' (Vollmer 2013 p. 60). Having lost a coordination equilibrium, the participants begin a scramble to re-establish cooperation by drawing on their 'practical sense' and their 'feel for the game' (Bourdieu 1990 pp. 66-67) in an effort to make sense of the situation. Vollmer (2013 pp. 62-68) argues that 'framing' 
(Goffman 1974) is a key mechanism by which participants produce the social context necessary to re-establish coordination. Hence, we should focus less on the disruptive event and more on 'tracing disruptiveness', because 'any collective impressed by a disruption is first and foremost impressed within a social situation' (p. 22). To trace disruptiveness, Vollmer refers to Whitehead (1929 pp. 30, 50) and Abbott (2001b p. 232) in calling for an extended understanding of social situations as a 'nexus of actual occasions'. Disruption is not an objective, exogenous event, but an endogenous reconfiguration in social order that plays out through processes of social interaction. It passes through turning points rather than instigating them from outside the social context. To understand technological change as disruption, we must focus on how individuals recognize disruption, how they communicate and enact it, and how these in turn transform social order. Keeping in mind the coconstruction of technology with its environment, the sociology of disruption outlined here lets us unpack the processes of co-construction and understand how and why certain framings of technology win out.

\section{Framing strategies and professional disruption}

This leads to the question of how, precisely, actors attempt to solve problems of punctuated cooperation - how are frames established, and by which strategies? Vollmer (2013 pp. 4762) suggests that actors draw on either normative, cognitive or relational keys in order to craft strategies that allow coordination equilibria to be re-established. The concept of 'keys' stems from Goffman, who made use of this musical metaphor to describe the signs, symbols and resources that actors draw upon when signalling the meaning of a social interaction they are 'correlation devices' for aligning expectations (Vollmer 2013 p. 48). This proceeds from the assumption that "sociocultural context is active, not passive; it gets negotiated rather than uncovered or invoked" (White 2008 p. xxi). We can develop Scott's metaphor of the 'dance' by adding keys that are needed to ensure that the music is in tune. Table 1 provides 
an overview of the typology of keys according to whether they are used to signal normative, cognitive or relational expectations. Signs, symbols and resources differ by their level of institutionalization: signs are immediately available, symbols are generalizations of signs that presuppose broader social conventions, and resources presuppose a collectively maintained infrastructure of socialization and habitualization (Vollmer 2013 pp. 51-53).

\section{$<$ INSERT TABLE 1 HERE $>$}

Incidentally, the layout in Table 1 makes it possible to draw in a number of parallels from the literature, based on the assertion that social actors have but three options available to them when considering a course of action: they can act according to what they think is morally right; they can act according to what they think is correct given the information they have at hand; or they can act according to their relations and positions vis-à-vis each other. One does not exclude the other, and most social action proceeds from a combination of keys deployed simultaneously, but the typology does seem exhaustive. Actors devise strategies with a respective focus on either asserting or contesting rights (normative), gathering, communicating or challenging information (cognitive), and breaking or forming coalitions (relational). Other theories in the relevant literature are placed in the table according to which types of keys they highlight in their accounts of social action. ${ }^{2}$ To take just one example from each category, Suddaby and Greenwood's (2005) 'rhetorical strategies of legitimacy' concern the effective deployment of normative keys in rhetorical strategies to promote or resist institutional change. Abbott's 'linked ecologies' (2005) framework meanwhile emphasize relational keys such as hinges, alliances and avatars that describe the different ways in which distinct ecologies can build coalitions. Finally, Seabrooke's (2014) 'epistemic arbitrage' emphasizes the use of cognitive keys in the contest between professionals to make their

\footnotetext{
2 The typology resembles Scott's (2008) framework of regulative, normative and cultural-cognitive pillars. The difference is that Vollmer's typology refers to the types of expectations that guide individuals, while Scott's refers to the institutions that guide organizations. Vollmer also sees normative keys as encompassing both formal and informal norms, while Scott splits these into regulative (formal) and normative (informal) institutions.
} 
expertise seem better suited to address a certain policy issue. While the table relates to any social situation, it is particularly pertinent in the system of professions due to their relatively large endowments of symbolic, cultural and social capital that lets them deploy these keys effectively.

Keys are socially mobilized in framing strategies. Actors draw on those keys that tend to defend the expectations cultivated by their practical sense or habitus (Vollmer 2013 pp. 62-67). When disruptions draw in actors from different ecologies, we can therefore expect competition between different frames, which travel across social situations and are reproduced and communicated through distinct forms of narrative, stories or style (White 2008). To accommodate disruptive issues, actors mix and match the cognitive, normative and relational keys they have available to construct frames that diagnose the issue, evaluate different solutions, and motivate others to act (Benford \& Snow 2000 p. 615). The different types of keys are not mutually exclusive, but mobilized simultaneously to create effective strategies. The mix of the different types of keys depends on habitus and design choice, and actors may choose to emphasise one type of key over another for strategic reasons. In this way, disruptions are brought under the auspices of norms, knowledge or social status respectively. Disruptions fizzle out and are normalized when the framing strategy is effective in re-establishing cooperation among participants. The cycle of disruption, to summarize, runs as follows: (1) disruptions are marked actively within the social context by some actors calling attention to the issue; (2) framing contests follow where actors draw on their practical sense in mobilizing different types of keys that signal how to accommodate the disruption; and (3) the disruption is either normalized if a framing strategy succeeds or challenged by a new marking of disruptiveness.

Framing contests take place within fields, which are given by the distribution of keys across participants who are involved in interconnected runs of social situations (Vollmer 
2013). When analysing how professionals and non-professionals interact to control disruptive issues, it is useful to think of this field as the organizational field. ${ }^{3}$ Organizational fields are relationally defined around issues (Wooten \& Hoffman 2008). Rather than a market or a technology, it is primarily issues or problems that form linkages between organizations that would otherwise not be present. For example, the issue of environmentalism in the chemical industry involves not only the industry itself and its buyers and suppliers, but also the government that regulates it, NGOs that pressure it, and insurance companies and law firms (Hoffman 1999). The field is the 'centre of common channels of dialogue and discussion' in which the issue gets treated by organizations that often have disparate purposes, attitudes and beliefs (Hoffman 1999 p. 352) and employ different logics and rhetorical strategies (Suddaby \& Greenwood 2005). Organizational fields are marked by contestation - they are 'arenas of power relations' (Brint \& Karabel 1991) or 'fields of struggles' (Bourdieu \& Wacquant 1992). In other words, this is where the framing contests take place.

Professionals are agents in organizational fields, but they are not completely determined by the field. Professionals have the agency to effect change in the organizational field through institutional work (Suddaby \& Viale 2011). They are guided and constrained by institutions, including the norms and expectations of their own profession, but they are also key agents driving institutional change. Framing contests have repercussions for the organizational field. For professionals, the organizational field is an important supply of keys: they are institutionalized to different degrees in the regulative, normative and culturalcognitive pillars of the field (Scott 2008). These keys are invoked in framing contests, but they are also less rigid during periods of punctuated cooperation. Disruptions are disruptive because existing institutions do not entirely suffice - they are challenged, their inadequacies

\footnotetext{
${ }^{3}$ Conceiving of these struggles as taking place within an organizational field means that material interests are differently understood compared to how they are typically assumed in other theories: rather than interests being unproblematically translated from actors' material environments, institutions are seen to define the ends and shape the means by which interests are determined and pursued (Scott 1991). In other words, institutions are prior to interests - they are the products of field-level engagement and not its inputs.
} 
made visible. ${ }^{4}$ Framing strategies therefore involve a degree of translation of existing institutions to bring them to bear on the issue at hand. This makes the institutions more flexible and open to interpretation, but also to challenge. For organizations, these periods involve increased interaction between internal and external institutions (Wooten \& Hoffman 2008 p. 141). Because of this, we often witness a re-arrangement of the organizational field as disruptions are normalized: "The endogenous order of punctuated cooperation thus sustained tends to be superseded, and often collectively marginalized, once disruptions are made subject to normalization" (Vollmer 2013 p. 106). Previously fringe institutions may shift into the centre of the field, or vice versa (Hoffman 1999 p. 365). For professionals and their organizations, the consequence is that engagement on technologically disruptive issues carries the risk of what I term professional disruption: the disruption of the institutional arrangements of a profession due to technological change. I see this as an example of institutional work (Lawrence \& Suddaby 2006).

\section{DATA AND METHODS}

I turn to the EU-level policy debate on e-cigarettes to study an empirical example of professional disruption. We are likely to observe framing contests deploying different keys in the regulatory debates over disruptive innovations such as e-cigarettes. The contending perspectives on what they represent, the variety of stakeholders, and the growth potential of the market all contribute to heated interactions. The analysis focuses on interactions between professionals and non-professionals in the organizational field around the issue of e-cigarette regulation. Studying professional disruption in this field entails that you look not only at the regulators of a specific policy issue, but also the various actors with which they 'frequently

\footnotetext{
${ }^{4}$ Suddaby and Viale (2011) understand this process as the opening of discursive spaces within an institutional order in the pursuit of professional projects. Disruptions, including those caused by technological change, do the same. While for Suddaby and Viale this is seen as a way for professionals to advance themselves, the present study suggests that it may just as often be a question of outsiders challenging the professions.
} 
and fatefully' interact: staff from other regulatory agencies, politicians, lobbyists, academics, activists, journalists, and so on. They are individuals making careers within the organizational field of a specific policy issue, with or without the help of more structured professional associations. Their claim to participation in the organizational field is relationally defined.

The EU is a particularly well-suited setting for the present investigation. E-cigarette regulation came on to the agenda in 2012 with the revision of the Tobacco Products Directive (TPD) (European Commission 2012a). Due to its unique political opportunity structure, with multiple layers of government and a complex institutional setup providing multiple access points to policy processes, the EU is an especially enticing arena for organized interests (Richardson 2000). This provides greater scope for professional competition to influence policy work, especially considering the 'thin' nature of the transnational domain as opposed to the 'thick' domestic domain, where jurisdictions are already populated and defended, leaving less scope for professionals to emerge and control issues (Seabrooke \& Tsingou 2015; Seabrooke 2014). In addition, the EU lobbying scene is very different from the U.S., for instance, emphasizing information-sharing and consensus-building rather than financial and legal tactics (Woll 2012). This makes it more likely that expertise plays a decisive role in European policy debates.

The study primarily draws on interview data to draw out the different interpretations of the policy issue, thereby making the different uses of keys and framing strategies apparent. The interviews were targeted at key actors in the organizational field. Table 2 below displays an overview of the key actors interviewed. The table also displays whether they belong to the tobacco control ecology, whether they are a public health or medical professional, and their organizational affiliation. The actors represent a sample of the most important actors involved in the policy arena. They were identified through desk research and referrals. The organizational field in the period under study was centred on the Parliament with institutional 
work carried out by a select group of Members of the European Parliament (MEPs), public health and tobacco control advocacy organizations, public affairs consultancies, firms and trade associations from the e-cigarette industry, and key figures in the 'vaping community' (e-cigarette users call themselves 'vapers'). Twenty-four interviews were conducted with the twenty-four different subjects - some were interviewed together and some were contacted for follow-up interviews to clarify certain points or supply additional detail. The majority of interviews were conducted in person, with some taking place over Skype or telephone. Interviews generally ran between one and two hours, the shortest being forty-five minutes and the longest being two and a half hours. Interviews were not recorded, putting subjects more at ease and allowing them to speak freer by fostering a sense of rapport (Alvesson 2003; Roulston 2010). Instead, notes were taken by hand during the interview, which were subsequently typed into lengthier transcriptions and field memos at the close of each interview.

The rows in the table that have been shaded dark grey represent interviewees who backed medicinal regulation, while unshaded rows represent those who argued against it, favouring no regulation at all or very light touch general product safety regulation. Rows shaded light grey are interviewees who took an intermediate position, meaning that they were in favour of a compromise position that incorporated elements of both medicinal and general product safety regulation. While the interviewees only represent a sample of the entire policy arena, they are all key persons who had an impact on the negotiations in this period. This is confirmed by document analysis of policy documents, meeting minutes, press releases, articles, and triangulation of data between the interviewees. Furthermore, as they occupy key positions in their respective organizations and in the policy arena generally, they can speak with confidence about developments and moves made by other actors in the organizational 
field. The empirical section references interview data by referring to the identifier numbers in the left-most column.

$<$ INSERT TABLE 2 HERE $>$

\section{E-CIGARETTE REGULATION IN THE EUROPEAN UNION}

E-cigarettes were invented by the Chinese pharmacist Hon Lik in the early 2000s (Grana et al. 2014). Also called personal vaporizers, they are devices that usually come in the form and size of a large pen. They contain a battery, a heating element and a nicotine-containing liquid solution. The solution is heated up to produce a mist or vapour rather than cigarette smoke. This produces the feel of smoking without the more harmful side effects of actually combusting tobacco leaves. Because of this, e-cigarettes are an attractive alternative to smokers in search of less harmful ways to enjoy their habit. Their appeal lies in being much closer to the sensation of regular smoking compared to pharmaceutical nicotine replacement therapy (NRT) products such as chewing gum, patches or inhalers. Thus, in addition to catching the interest of the big tobacco companies, pharmaceutical producers have also taken note of the possibility of marketing e-cigarettes as a smoking cessation tool. These characteristics, coupled with the growing social pressure on regular smoking, have paved the way for their rapid uptake (Boroujerdi 2014). Initially pushed by small, independent enterprises, big tobacco companies have taken notice of the profits being made and are starting to enter the e-cigarette market. All the major labels now own e-cigarette ventures (Grana et al. 2014). The WHO (2014 pp. 2-3), estimates that the market size grew to $\$ 3$ billion in 2014, and that at least half of the world's population live in countries that have reported the availability of e-cigarettes in their jurisdictions. Although they are presently a global phenomenon, market growth seems to have been most dramatic in the U.S. and Europe (where most statistics are also available). In the United Kingdom alone, the number of e- 
cigarette users has tripled from 700,000 in 2012 to 2.1 million in 2014 (Action on Smoking and Health 2014a).

The growing popularity of e-cigarettes has not been uncontroversial however. Fuelled by internet sales (Yamin et al. 2010), the market developed and evolved so fast that regulators were caught unaware. This led many people to describe the e-cigarette environment as a 'regulatory Wild West' (Woodruff 2014). Others have described it as a new golden age for tobacco companies mirroring that of the 1950-60s, who suddenly find themselves with new products to advertise and sell with little to no restriction (Rudin \& Alcock 2014). Worldwide regulatory answers vary widely between classifications of ecigarettes as either consumer products, tobacco products, or therapeutic products for medical use (World Health Organization 2014 p. 9); a range of responses that can even be found within the EU countries (European Commission 2012a p. A.3.1). At the heart of the regulatory debate lies the question of how e-cigarettes relate to existing tobacco or pharmaceutical policies. It is in other words a question of classification and categorization. What makes the regulatory debate very difficult to address is the fundamental uncertainty regarding their long-term use. According to some observers, it will take thirty or more years before epidemiology trails can quantify risks from e-cigarette use, with the potential caveat that we may never know 'because we are chasing a moving target in terms of the products and their development' (West \& Brown 2014 p. 442). Furthermore, there are a number of social and behavioural effects (the 'gateway drug' hypothesis chief among them) of growing e-cigarette use that are hard to determine and possibly specific to different cultural contexts.

Addressing e-cigarettes leaves regulators in a difficult position. Acting on the assumption that e-cigarettes will reduce the harms of smoking by serving either as a cessation tool or by replacing normal cigarettes, regulators are under pressure to set clear guidelines concerning their production, distribution and consumption. Policymakers are facing a 
dilemma: if they ban e-cigarettes, they could possibly forego a momentous opportunity to reduce the harm of smoking while securing tax revenues from a less harmful nicotine product - but if they support e-cigarettes, they risk providing tobacco companies with new sources of revenue and re-normalizing smoking, as well as exposing users to unknown long-term risks.

The revision of the Tobacco Products Directive (TPD) was set in motion in December 2012 with the adoption of the Commission's proposal, developed by the Directorate General for Health and Consumers (DG Sanco) under Commissioner Tonio Borg. Electronic cigarettes were initially not seen as an issue warranting much attention in the TPD. In the 2012 proposal, e-cigarettes were classified as nicotine containing products, which would be subject to medicinal regulation above a certain threshold of nicotine concentration (European Commission 2012b pp. 9-10). According to the interviews conducted, this classification was initially endorsed by the main groups in the European Parliament and the Council. Europe looked set for a medicinal regime for e-cigarettes. The surprising twist in the story occurred during the Parliamentary negotiations in 2013 when e-cigarettes suddenly became highly politicized and the most controversial part of the negotiations.

In the space of a few months, the European Parliament made a complete about-turn and struck down the proposed medicinal regulation. Initially, on the $24^{\text {th }}$ of July, 2013, the Committee on the Environment, Public Health and Food Safety (ENVI) adopted the report by chief rapporteur Linda McAvan on the proposed TPD in which all e-cigarettes would be subjected to medicinal regulation (European Parliament 2013a). Just over two months later, on the $8^{\text {th }}$ of October, 2013, the Parliament granted McAvan a negotiating mandate for the trilogue with the Council and Commission in which e-cigarettes would not be subjected to medicinal regulation unless they are presented as having curative or preventive properties (European Parliament 2013b). E-cigarettes with a nicotine concentration below $30 \mathrm{mg} / \mathrm{ml}$ could be sold as tobacco products, meaning that they should carry a health warning, should 
not be sold to anyone under 18 years of age, and should not be advertised. Following the trilogue, the adopted version of the TPD maintained these provisions, but reduced the nicotine concentration from $30 \mathrm{mg} / \mathrm{ml}$ to $20 \mathrm{mg} / \mathrm{ml}$ while also retaining some of the medicinal provisions from the original proposal. The case is therefore almost unprecedented in the EU: normally, if the Council and Commission agree on a course of action, it is almost guaranteed to become law. Here, the European Parliament succeeded in challenging both of these institutions. The key to the puzzle lies in unravelling the manoeuvres made by professional and non-professional groups and actors, and especially in the contest between the tobacco control ecology on the one hand and an alliance between vapers, the e-cigarette industry, liberal MEPs and certain public health professionals on the other. The investigation therefore focuses on these few crucial months in the Parliament from late July to early October in 2013 where the negotiations were the most intense and the effect these interactions had on the tobacco control ecology.

\section{Professional disruption in the revision of the Tobacco Products Directive}

The analysis will focus on three key questions as a way to organize the narrative and draw out the dynamics of professional disruption. First, why were e-cigarettes initially categorized as medicinal products in the Commission's proposal? Second, how was this classification overturned in the Parliamentary debates? Third, how did this affect the involved professionals, and especially those belonging to the public health and medical professions?

\section{Why were e-cigarettes initially categorized as medicinal products?}

As previously mentioned, e-cigarettes were seen as a fringe issue in the initial TPD proposal (interviewee $5,6,7) .{ }^{5}$ No one expected that they would become controversial and nearly

\footnotetext{
${ }^{5}$ Professionals from DG Sanco were not available for interviews due to pending lawsuits against the TPD. Several of the key policy actors interviewed, however, worked closely with DG Sanco and could provide insights into the proceedings there. DG Sanco has also made publicly available a large selection of policy documents and meeting minutes.
} 
threaten the survival of the entire Directive. At the beginning of negotiations, most policy actors outside the e-cigarette industry or community had not previously encountered ecigarettes. Given that they expected this to be a fringe issue, there was no reason to spend scarce resources exploring different regulatory options in depth. The impact assessment for the TPD identified medicinal regulation for nicotine containing products above a certain nicotine threshold to be the preferred option, and that threshold was set at $4 \mathrm{mg} / \mathrm{ml}$ in the proposal (European Commission 2012a, 2012b). At that level of concentration, the vast majority of the e-cigarette market would fall into the medicinal products category to ensure harmonized regulation (European Commission 2012a p. 80). This initial framing of ecigarettes came from the member states that had already embarked on the development of their own medicinal regulatory regime for e-cigarettes, in particular the United Kingdom (UK) (interviewee 8, 22). The UK has the most developed statistics on e-cigarette use due to the Smoking Toolkit Study (West \& Brown 2014). In addition, at the time they had one of the largest and fastest-growing markets for e-cigarettes in the EU, which caused public health advocacy organizations such as Action on Smoking and Health to focus on the issue, and the Medicines and Healthcare Regulatory Agency (MHRA) to engage with the issue from 2010 onwards. This contributed to building regulatory capacity (cf. Bach \& Newman 2007) in the UK which the EU could draw on. For example, the MHRA was invited to present at workshops in the European Parliament (interviewee 22).

The strength of the initial framing of e-cigarettes as medicinal products can be explained by how their disruptiveness was not marked by actors outside the tobacco control ecology. Rather, the disruption was quickly overcome and treated as a routine task in the course of preparing the TPD proposal. It is especially important to consider the professional links between public health and medical professionals and medicines regulators, and the lack of any such link between regulators and the nascent e-cigarette industry and vaping 
community. When e-cigarettes were flagged as a potentially disruptive issue by tobacco control professionals, they were framed as a public health threat. This frame consisted of two dimensions in particular. First of all, the normative keying of a public health threat was endorsed by public health bodies such as the WHO and the British Medical Association (BMA) (West \& Brown 2014). Tobacco control professionals derive the legitimacy for their policy proposals by deploying normative keys referring to the WHO in particular and the WHO Framework Convention on Tobacco Control (FCTC). Secondly, the frame mobilized cognitive and relational keys to place themselves as the right experts to treat the issue. Interestingly, the deployment of cognitive keys on the e-cigarette issue were motivated not by the availability of data, but by the lack of it. Essentially, the public health and medical professionals who initially claimed ownership of the issue argued that due to the lack of data concerning long-term risks, e-cigarettes could not be endorsed as a legitimate public health option - and they themselves were the right professionals to supply the needed data in the future (interviewee 4, 13). While the WHO and BMA are important organizational sources of legitimacy, their ultimate authority flows from scientific expertise. An essential element to the public health threat frame is this confession of ignorance and signalling of uncertainty (and therefore risk). Confessing ignorance was an effective way to construct a risk, but ultimately it is a weak cognitive key. Therefore, it was important that the disruption also be accommodated relationally by deepening the trust between tobacco control professionals and regulators.

Trust develops over time through social ties allowing 'frequent and fateful interaction' and the development of a shared meaning system (Granovetter 1973; Scott 1995 pp. 207209). In the case of tobacco controllers, this specifically meant an adherence to evidencebased policy and 'doing no harm'. Trust and frame coherence was especially established over time in the yearly meetings of DG Sanco's Regulatory Committee for Tobacco Control, 
which was put into place by the TPD revision in 2001. The Regulatory Committee consists of DG Sanco officials from the tobacco control unit and representatives from the health ministries of the Member States, sometimes including a select number of outside experts. In 2007, "new products" became a permanent agenda item on Committee meetings. ${ }^{6}$ The year after, e-cigarettes were explicitly identified as a regulatory issue, and the Commission agreed to prepare and disseminate an orientation note on the topic. The note provides a legal opinion on how e-cigarettes fit into the existing EU regulatory framework and indicates a preference for the pharmaceutical (medicinal) products definition (European Commission 2008). This preference was communicated directly to Committee members in the following year's meeting. The idea that novel tobacco and nicotine products should be strictly regulated by medicines regulators can be traced back to a 2004 report prepared for DG Sanco by a consortium of organizations from the tobacco control ecology, including the European Heart Network (EHN), the European Network for Smoking Prevention (ENSP), and the European Respiratory Society (ERS) (ASPECT Consortium 2004 p. 168). In the framing that emerged from the Regulatory Committee meetings, it is clear that e-cigarettes are put into the same category as other novel products that present a threat to existing regulatory measures. Before the TPD negotiations entered the Parliament, medical and health professionals in the Brussels-based tobacco control ecology unanimously agreed that medicinal products regulation was preferred (interviewee 1, 2, 4, 23). This was seen as an uncontroversial and common sense standpoint. In observing the progression from initial discussions in the Regulatory Committee meetings to orientation notes, impact assessments and the Proposal itself, we witness an increasing institutionalization of the public health threat frame.

Initially, professionals in the e-cigarette industry and the vaping community were unable to present a counter-frame. This was due in part to difficulties with access to the

6 Minutes from all Regulatory Committee meetings are available online at:
http://ec.europa.eu/health/tobacco/events/index_en.htm\#anchor7, accessed August 11, 2015 
medicines regulators and the lack of legitimacy for these professionals to challenge medical science - while the regulatory agencies were happy to meet medical practitioners, scientists and public health groups, it was difficult for professionals in the e-cigarette industry to gain meetings with the agencies (interviewee 22). The growing e-cigarette market in the EU therefore led to a period of punctuated cooperation that was accommodated by the deployment of a public health threat frame by the medical and public health professionals. The theory on punctuated cooperation suggests that strategies relying too much on cognitive keys are weak following disruptions due to the fundamental uncertainty surrounding them (Vollmer 2013 p. 106). Strategies that rely on normative and relational keys can effectively challenge cognitive claims. The public health community's cognitive claim on the e-cigarette issue was already weak as it was built on the lack of data rather than an abundance of it, but they were protected by the relational ties between them and the regulatory agencies. However, once the policy arena shifted from regulatory agencies such as the MHRA and DG Sanco to the European Parliament, the access problems that the e-cigarette industry and the vaping community were experiencing disappeared. This leads me to the second question.

\section{How was the initial classification overturned in the Parliamentary debates?}

The initial medicinal framing was overturned in the Parliament by professionals working for the e-cigarette industry and speaking for the vaping community, either directly or through public affairs consultancies, who deployed contending normative keys and built alliances to key MEPs. This is where the framing contest began in earnest. Several processes aligned during the crucial months from July to October 2013, which made the strategy exceedingly successful. The role of the vaping community was brought up by several interviewees $(5,6$, 7, 24). A substantial part of the e-cigarette market flows through internet sales channels (Yamin et al. 2010; Zhu et al. 2014). Due to the complexity of the market, users have been compelled to organize internet forums and YouTube channels to review and share 
information on the confusing array of products and liquids. There is also a large part of the community that is dedicated to tinkering with newer-generation e-cigarettes through mixing different batteries, tanks, atomizers and so on to create custom vaping experiences. Because of this, a significant subset of vapers are generally internet-savvy and highly active in multiple online forums, all of which communicate with each other and the e-cigarette industry, but do not share any formal, central organization (interviewee 18,22 ). They are also passionate about e-cigarettes, since many of them are convinced that their health and quality of life has improved, or that their lives have even been saved by e-cigarettes. They become almost religiously attached 'apostles of the product' and are adamantly opposed to big tobacco and smoking (interviewee 7). The threat of impending medicinal regulation, which would cause the majority of current e-cigarettes to be pulled from the market, mobilized the vapers in large numbers. A myth of an EU ban on e-cigarettes spread throughout the forums. ${ }^{7}$ E-cigarette companies did their part to alert their customers to the issue and spur them to action by flagging the issue on their websites and urging people to contact their MEPs (interviewee 18, 24). This resulted in what was described as a bombardment of the European Parliament by emails from concerned vapers to their MEPs (interviewee 4). The issue was brought high onto the political agenda in the TPD negotiations, especially by MEPs from the Alliance of Liberals and Democrats (ALDE) who found that 'free vaping' cohered well with liberal political values. Political capital could suddenly be gained by opposing medicinal regulation.

The massive public outcry from the vaping community constituted a second marking of disruptiveness in the sequence of e-cigarette regulation in the EU and a rejection of the public health threat frame. For most MEPs, their initial encounter with e-cigarettes was through emotional emails from their constituents rather than the scientific, medicinal framing

\footnotetext{
7 See for example the Facebook group "Vapers Against the EU Electronic Cigarette Ban": https://www.facebook.com/VaperAgainstTheBan, accessed September 4, 2015
} 
encountered in the regulatory agencies. This created a contending frame of e-cigarettes as recreational, reduced-risk devices to oppose the medicinal framing. The emotional dimension of the counter-frame and the way it contrasts with the technical language of the medicinal framing is important to consider. Highly emotional frames deepen the disruption - they make it harder for outsiders to ignore, drawing them in to the situation (Vollmer 2013 pp. 56-62). This both constitutes a more effective marking of disruptiveness and makes it easier to recruit allies.

The public outcry brought focus on the issue and presented an alternative interpretation, but they did not supply policymakers with legitimate regulatory options besides a complete hands-off approach, which was politically unfeasible due to the controversial, 'toxic' nature of the dossier (interviewee 12). A 'do nothing' option would be unacceptable given the starting point of medicinal regulation and the standpoint of the medical and health professionals. To turn the public outcry into politically feasible and pragmatic solutions required in-depth professional and policy process expertise by public affairs consultants (interviewee 10,11, 12). These consultants, working for clients in the e-cigarette industry, deployed normative and relational keys to construct a coalition around a compromise position retaining some elements of medicinal regulation, but promoting a tobacco products frame for e-cigarettes with nicotine concentrations under $30 \mathrm{mg} / \mathrm{ml}$.

Normatively, they appealed to the idea of tobacco harm reduction which is gaining momentum among certain public health professionals working on tobacco control, particularly in the UK and in the Nordic countries (Britton 2003; Hajek et al. 2014; Phillips 2009). The idea behind harm reduction, which originates in needle-exchange programmes to reduce the risk factors for HIV/AIDS and hepatitis among injecting drug users, is that beneficial public health outcomes may be better facilitated by measures aimed at mitigating the negative consequences of continued drug use instead of outright banning certain drugs. 
The norm of harm reduction has not enjoyed the same influence on tobacco control as it has on injection drugs. Harm reduction challenged the abstinence norm, which is the mainstream position in tobacco control and the default position of the WHO. Article 5.2(b) of the FCTC commits parties to reducing not only tobacco use, but also 'reducing nicotine addiction independently from its source' (World Health Organization 2014 p. 10). Therefore, the recreational use of nicotine is not a public health option under the treaty. In other words, harm reduction was still a fringe institution in the organizational field of tobacco control. Organizations in the centre of the field have strongly institutionalized the norm of abstinence. Relationally, the public affairs professionals built a coalition around the norm of harm reduction, which involved the e-cigarette industry, liberal MEPs, and certain public health professionals who had 'come out' in favour of harm reduction. Additionally, they relied on the vaping community to supply the 'lay expertise' (Wynne 1996) and anecdotal evidence supporting the framing of e-cigarettes as recreational devices, building an alternative 'network of expertise' (Eyal 2013) that circumvented the 'obligatory point of passage' of the central organizations of the tobacco control ecology (Latour 1988 pp. 43-9). By mobilizing the vaping community, it became possible to challenge the medicinal products framing by showing how poorly it cohered with actual use. The interviewees $(11,12)$ highlighted the importance of timing in these endeavours. Actions had to be taken at a precise moment in time when public opinion and political will aligned. In Scott's (2008) dance of institutional agency, at this point in time the rhythm was set by complex dynamics of political and public attention that transcend the ability of any one actor to impact. The issue takes on a life of its own, and participants have to rely on their practical sense and professional skills to keep dancing in the same rhythm. In other words: 'it's like a carousel - you either jump on it or you don't' (interviewee 12). Nonetheless, the coalition was successful in supplying the regulators with a workable political solution that normalized the disruption of e-cigarettes by 
rekeying them as reduced harm devices with broad political appeal. This brings us to the final question.

How did the framing contest affect the involved professionals?

The framing contest over the regulatory treatment of e-cigarettes resulted in professional disruption of the medical and public health professions. Where the abstinence norm used to be central in the institutional arrangement of the organizational field of tobacco control and in the habitus of the medical and public health professions that inhabit it, it is now competing with the harm reduction norm.

It is important to consider the unresolved issue of why the public health community was not effective in challenging the industry-organized harm reduction coalition. The answer lies in the centrality of the medical and public health professionals in the organizational field of tobacco control compared to the fringe positions occupied by the challenging coalition. The central tobacco control professionals reside in organizations that have strongly institutionalized the abstinence norm, for example by frequent referral to the WHO and the FCTC. These actors have less scope to explore frames and courses of action that deviate from their institutional environment. While these institutions have been instrumental in securing field centrality in the past, the disruption of e-cigarettes has enabled practices and opened discursive spaces that do not cohere well with the abstinence norm. These new practices and spaces were better captured by actors on the fringe, who are more institutionally flexible and therefore better placed to capitalize on alternative framings. Due to the limited social exposure of the initial framing contest, which took place among regulators and central actors in the organizational field, the inadequacy of the abstinence norm was not evident. Once the Parliament became involved, the frame could not survive the greater social exposure, and especially the outcry from the vaping community. 
The reason harm reduction used to occupy the fringes of the organizational field of tobacco control has to do with what some interviewees $(12,14,16)$ labelled the toxic environment' of the tobacco industry. Harm reduction will necessarily involve pragmatic policies that require some form of, if not cooperation, coordination with the tobacco industry. Although the vast majority of the e-cigarette market is controlled by small and medium-sized enterprises and not big tobacco (interviewee 8,21), all the big tobacco companies own ecigarette ventures today (Grana et al. 2014). Harm reduction policies concerning e-cigarettes will therefore involve big tobacco. Status 'leaks' through network relations (Podolny 2005), and any association with big tobacco is seen as toxic in tobacco control: 'there is no political or scientific capital to be gained by associating with tobacco companies' (interviewee 16). For many professionals working in tobacco control, the 'endgame' goal is to severely reduce the use of tobacco and the size and financial health of the industry (Fairchild et al. 2014; Malone et al. 2014; Thomson et al. 2012; Warner 2013). Article 5.3 of the FCTC, which is meant to insulate tobacco control policy from industry influence, has almost made it a law that public health officials cannot associate with the tobacco industry - to the point that they sometimes refuse to accept business cards from tobacco industry representatives (interviewee 14). An Action on Smoking and Health (2014b) briefing on e-cigarettes also cites 'tobacco company involvement in tobacco harm reduction' as 'a cause for concern'. While the WHO (2004, 2014 p. 1) endorses harm reduction in needle exchange programs, it recognizes that the issue is controversial in tobacco control. In sum, harm reduction does not fit with the institutionalization of abstinence and the endgame ideal.

Evidence of the professional disruption of the medical and public health profession engaged on tobacco control is clear in the WHO statement quoted in the Introduction, but it can be supplemented with statements from the interviewees. Especially the position of the European Public Health Alliance (EPHA) is illuminating in this regard - they function as a 
hub for a number of public health organizations and are responsible for coordinating strategies (interviewee 23). Before the TPD negotiations entered Parliament, there was clear agreement among their member base on the medicinal products position. Over the turbulent summer months of 2013, the issue became increasingly controversial and EPHA members divided into a harm reduction and abstinence camp. This can also be corroborated by comparing a May 2013 EPHA position paper on the TPD revision with a December 2013 EPHA briefing on e-cigarettes (European Public Health Alliance 2013a, 2013b). The position paper makes a united case for medicinal products regulation, while the briefing paper comes with the disclaimer that it does not reflect the views of all members, even though it is much more open-ended in considering different regulatory options. According to the interviewee from EPHA, it had been impossible to draft a common position paper on e-cigarettes in the fall of 2013, although this was the original goal. This indicates a clear challenge and displacement of abstinence as the central institution within both the organizational field and the medical and public health professions.

An interviewee (4) from the European Respiratory Society noted how the schism was very evident among its member base, and seemed to loosely (but not exactly) follow the lines of medical professionals (abstinence) versus public health professionals (harm reduction), which was also the case in EPHA (interviewee 23). Due to the lack of data, the ERS had to balance the views of the members and put forward an average position, which 'made it hard to act effectively or forcefully in the policy debate'. This was a problem encountered by other public health NGOs as well (interviewee 1,2). There is also evidence of vicious, stigmatizing attacks among the interviewees to discredit the normative base of the other camp. For example, a medical professional (interviewee 13) stated that harm reduction was an industry term that came from light and low tar cigarettes and she would never use it nor endorse it. Conversely, many in the harm reduction camp spoke disparagingly about the abstinence norm 
as the 'quit or die' approach (interviewee 15, 17, 18). The logic of this schism between medical and public health professionals may derive from how their respective professions have institutionalized the norm of evidence-based policy to a different degree. Medical professionals are the more strictly, abstractly scientific of the two, whereas public health requires some degree of interaction with concrete, social and political realities. This should allow them more scope to experiment with harm reduction, while medical professionals are first required to uncover the scientific evidence for the approach. The disruption therefore challenged not only internal professional and organizational institutions, but also (and as a result thereof) organizational alliances. From initially controlling the issue and the dominant frame for e-cigarette regulation, the medical and public health professionals in the tobacco control community ended up in a state of professional disruption following the strategic moves of competing actors in the European policy arena.

\section{DISCUSSION}

The insights developed here are meant to be applicable across a range of cases in which professions are challenged by technological change. I will briefly touch on a few examples, but restrict myself to health-related issues. Although I am not arguing that professional disruption only occurs in health, the fact that it is a highly professionalized sphere of society that also experiences much technological change creates fertile ground for professional disruption.

The tobacco control ecology in the EU has previously faced challenges from new technologies, the case of Swedish 'snus' (a type of oral tobacco) being a prominent example. In the case of snus, the EU has banned its sale outside Sweden, but granted Sweden an exemption to secure their accession to the Union in 1995. The scientific basis for the ban has been the subject of much controversy (Fagerström \& Schildt 2003). As with e-cigarettes, the 
product has a risk profile much less harmful than conventional smoking (ENVIRON International Corporation 2010). Regulators therefore faced the same dilemmas: do you ban a less harmful product that could offset some of the harms from conventional smoking, or do you allow a new tobacco product to enter European markets with uncertain effects?

There are good arguments in favour of lifting the ban on snus. Sweden and Denmark have similar usage rates of tobacco, but Sweden has much lower rates of tobacco-related illnesses and mortality rates, leading to what is sometimes called the 'Swedish Paradox' in tobacco control (Fagerström \& Schildt 2003). This is because two-thirds of Swedish tobacco use is oral rather than smoking. There seems to be a good opportunity to deploy cognitive keys to make the case for lifting the snus ban, which Swedish Match has attempted several times (interviewee 14, 15, 19, 20). However, the snus ban has stayed in place through each revision of the TPD. In this case, the cognitive keys could not overturn a stronger normative key of abstinence because the social capital has been missing. There is no pan-European snus community ready to mobilize against a perceived unjust ban. Swedish users, being exempt from the ban, have no reason to mobilize.

Some snus proponents in the EU tried to link the issue to e-cigarettes, but the ecigarette coalition denied them the opportunity, and the required social capital, due to fears that it would endanger their own project (interviewee 12). The toxic environment of tobacco extends to oral tobacco companies, and status leaks through network ties (Podolny 2005). While professionals promoting snus can make legitimate appeals to the norm of harm reduction, they have no effect if the keys are not mobilized through social relations. Therefore, the internal coherence of the tobacco control ecology was not challenged in the snus case - there was no professional disruption. Relational keys matter, but only in connection with cognitive or normative keys. For example, if the 'Vaportini' (Daily Mail 2014), a device for inhaling alcohol vapours, was hypothetically banned, we might expect 
maligned bar guests and partygoers to voice their grievances - but which cognitive or normative keys could credibly be deployed in their favour, and by which professional group? It is unlikely that such a ban would have any chance of being overturned. This indicates that the strength of the harm reduction coalition in the e-cigarette case derived from a combination of the normative rekeying by professionals backed by the social capital of the vaping community - their combination amounted to more than the sum of their parts.

Studies on the social origins of the 'autism epidemic' are similarly related to the topics I raise in this paper (Eyal 2013; Eyal et al. 2010). Eyal and his colleagues argue that the precipitous rise in cases of autism in Western countries is best explained by the deinstitutionalization of mental retardation in the 1970s. Before the 1970s, child psychiatrists had a monopoly on the diagnosis of autism, and treatment was modelled on a medical paradigm of hospitalization and treatment in search of a cure. When cures failed to materialize, aggrieved parents and psychologists formed an alternative network of expertise based on therapy, which parents could administer without the need for hospitalization. They circumvented the obligatory passage point of the child psychiatrist, but this was only made possible by new diagnostic technologies: the proliferation of diagnostic checklists that allowed parents and psychologists to score and standardize autism diagnosis. The monopoly of the psychiatric profession was disrupted by a shrewd combination of relational ties and normative keys about how autistic children ought to be treated made possible by the use of a new technology.

Similar to the e-cigarette case, the autonomy of the defending profession to define ills and correct them without participation from the targets or patients seems like a strength initially, but is eventually revealed to be a weakness. Eyal (2013 pp. 875-6) distinguishes between the power of experts and expertise. While experts derive their power from autonomy (control over the demand of its services) and monopoly (control over the supply of their 
services), the power of expertise derives from its generosity (being framed in terms that make it useful and understandable) and co-production (involving a variety of stakeholders). The lacking generosity of the expertise of child psychiatry before the 1970s and tobacco control in the TPD revision allowed alternative networks of expertise to redefine the issues in terms coproduced and more aligned with the interests of users. Exchange or dialogue is needed to increase the influence of expertise. One-way transcriptions from bases of expertise towards their targets are vulnerable, in these cases, to two-way transcriptions that co-produce expert knowledge by drawing on local and practical details.

Studies on the development of medical knowledge on glaucoma also strongly suggest the ubiquity of co-constitutive effects between technologies, expertise and their sociopolitical context (Consoli \& Ramlogan 2008, 2012). This puts a strong challenge to the use of 'linear models that present the connection between basic science and the development of new technologies as a unidirectional process' (Consoli \& Ramlogan 2008 p. 53), as well as making apparent the naivety of the view that policy considerations should centre on translating science into policy. The glaucoma studies also reveal similar dynamics of professional disruption identified in the e-cigarette case. The inability of early medical paradigms in glaucoma treatment to provide satisfactory cures led to the definition of new research areas, new problems, and new technologies to probe those problems. For example, when hereditary factors were found to be significant following epidemiology studies in the 1970s, this led to cross-disciplinary interactions with the field of molecular genetics in the 1990s (p. 43). Before the 1970s, nearly all scientific publications on glaucoma were within the field of ophthalmology, but in the decades since nearly half of publications fall outside the traditional boundaries of the discipline (p.45-6). Other technologies such as lasers and computers have also contributed to diagnostic advances in glaucoma while disrupting ophthalmology. This allows new professions and new forms of expertise to encroach on the 
territory, but they also enrich it by defining new problems and building the knowledge base. The dynamism of the system of medical knowledge on glaucoma comes from the complementary processes of problem-finding and problem-solving: 'the search for solutions at any time is directed by the interpretative system through which problems are first defined' (Consoli \& Ramlogan 2008). This echoes Abbott's (1988 p. 314) and Eyal's (2013) call for a history of 'tasks and problems' instead of a history of groups. ${ }^{8}$ When studying technologies and professional change, it is equally important to pay attention to both the problems and the solutions around which the technologies are constructed.

What is the problem being addressed by the tobacco control ecology in the e-cigarette case study? There are two different ways to phrase it, which cohere with the harm reduction and abstinence camps, respectively. The problem might be phrased as the fact that $26 \%$ of Europeans are smokers and hence victims of nicotine addiction (European Commission 2015). According to the WHO, smokers suffer from 'tobacco dependence syndrome', which is classified as a disease (World Health Organization n.d.). The solution to that problem is to cure the disease helping smokers quit or making it more expensive, difficult and socially unacceptable to smoke. This has been the path pursued by most states once the harmful effects of smoking were accepted. E-cigarettes are only a part of that solution to the extent that they serve as quitting tools, as a new form of nicotine replacement therapy. A different way to phrase the problem might be thus: smoking is a harmful leisure activity. The solution to this problem is to make smoking less harmful. This requires that nicotine addiction in itself is not seen as a problem, but that the delivery of the drug is the real issue, as reflected in the often-quoted words of Russell (1976): 'People smoke for the nicotine but they die from the tar'. If e-cigarettes are as satisfying to use as conventional cigarettes, and if the best medical estimate that they are $95 \%$ less harmful is correct (McNeill et al. 2015), then e-cigarettes are

\footnotetext{
${ }^{8}$ This also supports Hoffman's (1999) assertion that organizational fields are located around issues, not markets or technologies.
} 
very much a part of the solution. The harm reduction approach also has the significant benefit that most vapers do not see themselves as being ill (interviewee 22). We might expect the influence of harm reduction expertise to keep increasing simply because it is more generous than the abstinence approach (Eyal 2013).

The use of e-cigarettes over the years will lead to new insights, new problems, new solutions, and therefore, new iterations of feedback loops between the technology and its social context. Their use and interpretation will keep evolving. There is currently a shift in medical knowledge towards replacing the imperative of finding a cure with finding workable solutions that satisfice and can be improved upon (Consoli \& Ramlogan 2012 p. 315; Saltus 2008). Although smoking rates have declined in the developed world, the past decades of tobacco control have not found a cure to the smoking problem - maybe smoking needs to be improved upon rather than cured? For policymakers, the implication of the study is clear: to appreciate the generous dimension of expertise as opposed to the autonomy of experts, thereby supporting policy solutions that have real traction with their intended targets and incur less cultural resistance. The institutions on which medical expertise rests are not unchanging. The e-cigarette study and the glaucoma study both highlight the disruptive potential of technologies to alter the assumptions and norms on which a profession rests. Glaucoma research has gone through several such disruptive shifts - e-cigarettes are causing tobacco control to go through one currently. It would be unwise to cling unquestioningly to past institutions.

\section{Conclusion}

This paper has studied one example of a fast process of professional change in detail. I have argued that while much ground has been covered on questions of slower, gradual and longerrunning processes of professional change, there are good reasons to pay attention to 
individual examples of more sudden and jolting change, especially those brought about by new technologies. These periods can be thought of as periods of 'punctuated cooperation' (Vollmer 2013), in which professionals and non-professionals deploy cognitive, normative and relational keys to re-establish cooperation by framing the 'tasks and problems' (Abbott 1988 p. 314; Eyal 2013) raised by the technology in ways that allow them to carry out meaningful work. Actors draw on keys from their institutional environment when designing framing strategies, but as a consequence of social interaction and contestation during the period of punctuated cooperation, they often find these environments irrevocably changed when disruptions are normalized. For professionals who are called upon to address issues of disruptive technology, this can lead to a state of professional disruption. In the case of ecigarette regulation in the EU, this resulted in a strong challenge to the central institution of abstinence in the organizational field of tobacco control. Professionals in this field are now more divided than previously, and professional and organizational alliances are being called into question.

The study therefore contributes in a number of areas while raising new questions for research. First of all, the study advances research on professionals as institutional workers (Suddaby \& Viale 2011) and the institutionalist sociology of the professions (Muzio et al. 2013) by looking more closely at the interaction between technological change and the institutions of the profession. Here it call attention to the importance for future research of considering how professionals and non-professionals interact when they navigate and negotiate their institutional environments. Second, the study makes an intervention within research on organizational fields, suggesting that there is much value to be gained by opening up the black box of the single, disruptive event and focusing analytical attention on the processes that occur as it unfolds. For future research, it would be valuable to consider the empirical conditions under which disruptive events come to have particularly meaningful 
impacts on the field. While disruptions are always marked and constructed within a social context, that does not make the empirical conditions unimportant. Why are some disruptions more impactful than others? Finally, the study should also be of interest to scholars of regulation and governance, especially in the transnational domain, in which an increasing share of work is falling to professionals who organize across national boundaries (Faulconbridge \& Muzio 2012; Seabrooke 2014). Here it has provided potentially useful theory that can be brought to bear on disruptions in these domains, whether they stem from technological change or otherwise.

In the 'dance' of institutional agency (Scott 2008) that has been analysed in this study, it is clear that professionals have played a leading role in 'supplying the choreography' of political economic transformations, but they cannot control who joins the dance or how it unfolds. While the tobacco control ecology successfully supplied the initial framings of ecigarettes towards regulatory agencies, the sudden mobilization of the vaping community and their interaction with other actors in the policy subsystem resulted in a series of events that led to the eventual disruption of the medical and public health professions. What is still not clear, and what presents an interesting area for continued research, is how the rhythm of the dance is set and how it changes the moves of the actors. The interviewees in the e-cigarette case did not feel in control of the rhythm themselves - they had to dance while the music was playing, or jump on the carousel while it was spinning. Issues of timing, tempo and sequence warrant more attention in studies of professional and institutional change. A core question raised by the study thus has to do with uncovering the interaction between slow and fast processes of change. When do we know we are looking at one and not the other, and how do they interrelate? 


\section{References}

Abbott, A. (1988). The system of professions: An essay on the division of expert labor. Chicago \& London: University of Chicago Press.

—. (2001a). On the Concept of Turning Point. Time Matters: On Theory \& Method, pp. 240-60. University of Chicago Press: Chicago \& London.

—. (2001b). Temporality and Process in Social Life. Time Matters: On Theory \& Method, pp. 209-39. University of Chicago Press: Chicago \& London.

- (2005). Linked Ecologies: States and Universities as Environments for Professions. Sociological Theory, 23/3: 245-74.

Action on Smoking and Health. (2014a). Use of electronic cigarettes in Great Britain. Retrieved from <http://www.ash.org.uk/files/documents/ASH_891.pdf>

- (2014b). Electronic cigarettes (also known as vapourisers). Retrieved from <http://www.ash.org.uk/files/documents/ASH_715.pdf>. DOI: 10.1161/CIRCULATIONAHA.114.008545

Alvesson, M. (2003). Beyond Neopositivists, Romantics, and a Reflexive Approach To Localists: in Organizational Research. Academy of Management Rev, 28/1: 13-33. DOI: 10.5465/amr.2003.8925191

ASPECT Consortium. (2004). Tobacco or Health in the European Union: Past, Present and Future. Luxembourg. Retrieved from $<$ http://ec.europa.eu/health/archive/ph_determinants/life_style/tobacco/documents/tobac co_fr_en.pdf>

Bach, D., \& Newman, A. L. (2007). The European regulatory state and global public policy: micro-institutions, macro-influence. Journal of European Public Policy, 14/6: 827-46. DOI: $10.1080 / 13501760701497659$

Benford, R. D., \& Snow, D. A. (2000). Framing Processes and Social Movements: An Overview and Assessment. Annual Review of Sociology, 26/1974: 611-39. DOI: 10.1146/annurev.soc.26.1.611

Boroujerdi, R. D. (2014). The Search for Creative Destruction. Retrieved from $<$ http://www.goldmansachs.com/investor-relations/financials/current/annualreports/2013-annual-report-files/search.pdf>

Bourdieu, P. (1990). In Other Words: Essays Towards a Reflexive Sociology. Stanford: Stanford University Press.

Bourdieu, P., \& Wacquant, L. (1992). Invitation to Reflexive Sociology. Chicago \& London: University of Chicago Press.

Bower, J. L., \& Christensen, C. M. (1995). Disruptive Technologies: Catching the Wave. 
Harvard Business Review, 43-53.

Brint, S. (1994). In an Age of Experts: The Changing Roles of Professionals in Politics and Public Life. Princeton: Princeton University Press.

Brint, S., \& Karabel, J. (1991). Institutional Origins and Transformations: The Case of American Community Colleges. Powell W. W. \& Dimaggio P. J. (eds) The New Institutionalism in Organizational Analysis, pp. 337-60. University of Chicago Press: Chicago \& London.

Britton, J. (2003). Smokeless tobacco: Friend or foe? Addiction, 98/9: 1199-201. DOI: 10.1046/j.1360-0443.2003.00480.x

Brock, D. M., Leblebici, H., \& Muzio, D. (2014). Understanding professionals and their workplaces: The mission of the Journal of Professions and Organization. Journal of Professions and Organization, 1/1: 1-15. DOI: 10.1093/jpo/jot006

Carr, E. H. (1961). What is History? New York: Vintage Books.

Christensen, C. M. (1997). The Innovator's Dilemma: When New Technologies Cause Great Firms to Fail. Harvard Business School Press.

Christensen, C. M., \& Raynor, M. E. (2003). The Innovator's Solution: Creating and Sustaining Successful Growth. Harvard Business School Press.

Chwieroth, J. (2007). Neoliberal economists and capital account liberalization in emerging markets. International organization, 61/02: 443-63.

Coffee, J. C. (2006). Gatekeepers: The Professions and Corporate Governance. Oxford: Oxford University Press.

Consoli, D., \& Ramlogan, R. (2008). Out of sight: Problem sequences and epistemic boundaries of medical know-how on glaucoma. Journal of Evolutionary Economics, 18/1: 31-56. DOI: 10.1007/s00191-007-0074-4

- (2012). Patterns of organization in the development of medical know-how: The case of glaucoma research. Industrial and Corporate Change, 21/2: 315-43. DOI: 10.1093/icc/dtr043

Cooper, D. J., \& Robson, K. (2006). Accounting, professions and regulation: Locating the sites of professionalization. Accounting, Organizations and Society, 31: 415-44. DOI: 10.1016/j.aos.2006.03.003

Daily Mail. (2014). Is this the most dangerous cocktail yet? Toxic trend for inhaling alcohol arrives in UK ahead of summer festival season. Daily Mail Online. Retrieved May 30, 2015, from <http://www.dailymail.co.uk/femail/article-2575542/Is-dangerous-cocktailToxic-trend-inhaling-alcohol-arrives-UK-ahead-summer-festival-season.html>

Dimaggio, P. J. (1991). Constructing an organizational field as a professional project: US Art Museums, 1920-1940. Powell W. W. \& Dimaggio P. J. (eds) The New Institutionalism 
in Organizational Analysis, pp. 267-92. University of Chicago Press: Chicago.

ENVIRON International Corporation. (2010). Review of the Scientific Literature on Snus (Swedish Moist Snuff). Arlington.

European Commission. (2008). Orientation Note: Electronic Cigarettes and the EC Legislation. Brussels.

Retrieved

from $<$ http://ec.europa.eu/health/archive/ph_determinants/life_style/tobacco/documents/orient ation_0508_en.pdf>

- (2012a). Impact Assessment accompanying the document "Proposal for a Directive of the European Parliament and of the Council on the approximation of the laws, regulations and administrative provisions of the Member States concerning the manufacture, presentation.. Brussels. Retrieved from <http://ec.europa.eu/health/tobacco/docs/com_2012_788_ia_en.pdf>

- (2012b). Proposal for a Directive of the European Parliament and of the Council on the approximation of the laws, regulations and administrative provisions of the Member States concerning the manufacture, presentation and sale of tobacco and related $\begin{array}{lll}\text { products. } & \text { Brussels. } & \text { Retrieved }\end{array}$ <http://ec.europa.eu/health/tobacco/docs/com_2012_788_en.pdf>

- (2015). Special Eurobarometer 429: Attitudes of Europeans towards tobacco and electronic cigarettes. Brussels. Retrieved from <http://ec.europa.eu/public_opinion/archives/ebs/ebs_429_sum_en.pdf>

European Parliament. (2013a). 2012/0366(COD) - 24/07/2013 Committee report tabled for plenary, 1st reading/single reading. European Parliament Legislative Observatory. Retrieved May 30, 2015, from <http://www.europarl.europa.eu/oeil/popups/summary.do?id=1289257\&t=e\&l=en>

—. (2013b). 2012/0366(COD) - 08/10/2013 Text adopted by Parliament, partial vote at 1st reading/single reading. European Parliament Legislative Observatory. Retrieved May 30 , 2015 , from

<http://www.europarl.europa.eu/oeil/popups/summary.do?id=1316840\&t=e\&l=en>

European Public Health Alliance. (2013a). EPHA Position Paper: Revision of the Tobacco Products Directive. Brussels. Retrieved from <http://www.epha.org/IMG/pdf/EPHA_position_on_the_TPD_May_2013.pdf>

- (2013b). EPHA Briefing: Regulatory options for Nicotine-Containing Products (NCP) in the EU. Brussels. Retrieved from $<$ http://www.epha.org/IMG/pdf/EPHA_briefing_on_regulation_of_NCPs-December2.pdf>

Evetts, J. (2003). The Sociological Analysis of Professionalism: Occupational Change in the Modern World. International Sociology, 18/2: 395-415. DOI: 10.1177/0268580903018002005 
Eyal, G. (2013). For a Sociology of Expertise: The Social Origins of the Autism Epidemic. American Journal of Sociology, 118/4: 863-907.

Eyal, G., Hart, B., Oncular, E., Oren, N., \& Rossi, N. (2010). The Autism Matrix. Cambridge: Polity Press.

Fagerström, K. O., \& Schildt, E. B. (2003). Should the European Union lift the ban on snus? Evidence from the Swedish experience. Addiction, 98/9: 1191-5. DOI: 10.1046/j.13600443.2003.00442.x

Fairchild, A. L., Bayer, R., \& Colgrove, J. (2014). The Renormalization of Smoking? ECigarettes and the Tobacco 'Endgame'. The New England Journal of Medicine, 370/4: 293-5. DOI: 10.1056/NEJMp1415160

Faulconbridge, J. R., \& Muzio, D. (2012). Professions in a globalizing world: Towards a transnational sociology of the professions. International Sociology, 27/1: 136-52.

Fourcade, M., \& Khurana, R. (2013). From social control to financial economics: the linked ecologies of economics and business in twentieth century America. Theory and Society, 42/2: 121-59. DOI: $10.1007 / \mathrm{s} 11186-012-9187-3$

Freidson, E. (2001). Professionalism: The Third Logic. Chicago: University of Chicago Press.

Goffman, E. (1974). Frame Analysis: An Essay on the Organization of Experience. Cambridge: Harvard University Press.

Grana, R., Benowitz, N., \& Glantz, S. a. (2014). E-cigarettes: a scientific review. Circulation, 129/19: 1972-86. DOI: 10.1161/CIRCULATIONAHA.114.007667

Granovetter, M. S. (1973). The strength of weak ties. American Journal of Sociology, 78/6: 1360. DOI: $10.1086 / 225469$

Hajek, P., Etter, J.-F., Benowitz, N., Eissenberg, T., \& McRobbie, H. (2014). Electronic cigarettes: review of use, content, safety, effects on smokers and potential for harm and benefit. Addiction (Abingdon, England), 1801-10. DOI: 10.1111/add.12659

Henriksen, L. F., \& Seabrooke, L. (2015). Transnational organizing: Issue professionals in environmental sustainability networks. Organization. DOI: $10.1177 / 1350508415609140$

Hoffman, A. J. (1999). Institutional Evolution and Change: Envrionmentalism and the U.S. Chemical Industry. The Academy of Management Journal, 42/4: 351-71. DOI: $10.2307 / 257008$

Johnson, T. J. (1972). Professions and Power. London: Macmillan.

Larson, M. S. (1977). The Rise of Professionalism. Berkeley and Los Angeles: University of California Press.

Latour, B. (1987). Science in Action. Cambridge, Mass.: Harvard University Press. 
. (1988). The Pasteurization of France. Cambridge, Mass.: Harvard University Press.

(1993). We Have Never Been Modern. Cambridge: Harvard University Press.

Lawrence, T. B., \& Suddaby, R. (2006). Institutions and Institutional Work. Clegg S. R., Hardy C., Lawrence T. B., \& Nord W. R. (eds) The SAGE Handbook of Organization Studies, Second Edi. SAGE Publications: London.

Lebaron, F. (2001). Economists and the economic order: The field of economists and the field of power in France. European Societies, 3/1: 91-110. DOI: $10.1080 / 14616690120046969$

Leblebici, H., Salancik, G. R., Copay, A., \& King, T. (1991). Institutional Change and the Transformation of Interorganizational Fields: An Organizational History of the U.S. Radio Broadcasting Industry. Administrative Science Quarterly, 36/3: 333-63. DOI: $10.2307 / 2393200$

Malone, R., McDaniel, P., \& Smith, E. (2014). It is time to plan the tobacco endgame. BMJ (Clinical research ed.), 348: g1453. BMJ Publishing Group Ltd. DOI: 10.1136/bmj.g1453

McNeill, A., Brose, L. S., Calder, R., Hitchman, S. C., Hajek, P., \& McRobbie, H. (2015). Ecigarettes: an evidence update. London. Retrieved from <https://www.gov.uk/government/uploads/system/uploads/attachment_data/file/457102/ Ecigarettes_an_evidence_update_A_report_commissioned_by_Public_Health_England_ FINAL.pdf>

Mennicken, A. (2010). From inspection to auditing: Audit and markets as linked ecologies. Accounting, Organizations and Society, 35/3: 334-59. Elsevier Ltd. DOI: 10.1016/j.aos.2009.07.007

Munir, K. A., \& Phillips, N. (2005). The Birth of the 'Kodak Moment': Institutional Entrepreneurship and the Adoption of New Technologies. Organization Studies, 26/11: 1665-87. DOI: 10.1177/0170840605056395

Muzio, D., Brock, D. M., \& Suddaby, R. (2013). Professions and Institutional Change: Towards an Institutionalist Sociology of the Professions. Journal of Management Studies, 50/5: 699-721. DOI: 10.1111/joms.12030

Noordegraaf, M. (2007). From 'Pure' to 'Hybrid' Professionalism. Present-Day Professionalism in Ambiguous Public Domains. Administration \& Society, 39/6: 76185.

Phillips, C. V. (2009). Debunking the claim that abstinence is usually healthier for smokers than switching to a low-risk alternative, and other observations about anti-tobacco-harmreduction arguments. Harm reduction journal, 6: 29. DOI: 10.1186/1477-7517-6-29

Podolny, J. M. (2005). Status signals: A sociological study of market competition. Princeton University Press. 
Reay, T., \& Hinings, C. R. (2005). The recomposition of an organizational field: Health care in Alberta. Organization Studies, 26/3: 351-84. DOI: 10.1177/0170840605050872

Richardson, J. (2000). Government, Interest Groups and Policy Change. Political Studies, 48: 1006-25. DOI: 10.1111/1467-9248.00292

Rogers, E. M. (2003). Diffusion of Innovations, 5th editio. New York: Simon and Schuster.

Roulston, K. (2010). Considering quality in qualitative interviewing. Qualitative Research, 10/2: 199-228. DOI: 10.1177/1468794109356739

Rudin, M., \& Alcock, C. (2014). Burning Desire: The Seduction of Smoking. United Kingdom: British Broadcasting Corporation (BBC).

Russell, M. A. (1976). Low-tar medium-nicotine cigarettes: a new approach to safer smoking. British Medical Journal, 1/6023: 1430-3. DOI: 10.1136/bmj.1.6023.1430

Saltus, R. (2008). What is a cure? Paths of Progress (Dana-Farber Cancer Institute), Fall/Winter.

Scott, W. R. (1991). Unpacking Institutional Arguments. Dimaggio P. J. \& Powell W. W. (eds) The New Institutionalism in Organizational Analysis, pp. 164-82. University of Chicago Press: Chicago \& London.

—. (1995). Institutions and Organizations. London: Sage.

- (2008). Lords of the Dance: Professionals as Institutional Agents. Organization Studies, 29/2: 219-38. DOI: 10.1177/0170840607088151

Seabrooke, L. (2014). Epistemic Arbitrage: Transnational Professional Knowledge in Action. Journal of Professions and Organization, 1/1: 49-64.

Seabrooke, L., \& Tsingou, E. (2014). Distinctions, affiliations, and professional knowledge in financial reform expert groups. Journal of European Public Policy, 21/3: 389-407. Taylor \& Francis. DOI: 10.1080/13501763.2014.882967

- (2015). Professional emergence on transnational issues: Linked ecologies on demographic change. Journal of Professions and Organization, 2/1: 1-18. DOI: 10.1093/jpo/jou006

Stone, D. (2013). 'Shades of grey': the World Bank, knowledge networks and linked ecologies of academic engagement. Global Networks, 13/2: 241-60. DOI: 10.1111/glob. 12007

Suddaby, R., Cooper, D. J., \& Greenwood, R. (2007). Transnational regulation of professional services: Governance dynamics of field level organizational change. Accounting, Organizations and Society, 32: 333-62. DOI: 10.1016/j.aos.2006.08.002

Suddaby, R., \& Greenwood, R. (2005). Rhetorical Strategies of Legitimacy. Administrative Science Quarterly, 50/1: 35-67. 
Suddaby, R., \& Viale, T. (2011). Professionals and field-level change: Institutional work and the professional project. Current Sociology, 59/4: 423-42. DOI: $10.1177 / 0011392111402586$

Thomson, G., Edwards, R., Wilson, N., \& Blakely, T. (2012). What are the elements of the tobacco endgame? Tobacco control, 21/2: 293-5. BMJ Publishing Group Ltd. DOI: $10.1136 /$ tc. 2010.040881

Vollmer, H. (2013). The Sociology of Disruption, Disaster and Social Change: Punctuated Cooperation. Cambridge: Cambridge University Press.

Warner, K. E. (2013). An endgame for tobacco? Tobacco control, 22 Suppl 1/suppl_1: i3-5. DOI: 10.1136/tobaccocontrol-2013-050989

Wejnert, B. (2002). Integrating Models of Diffusion of Innovations: A Conceptual Framework. Annual Review of Sociology, 28/1: 297-326. DOI: 10.1146/annurev.soc.28.110601.141051

West, R., \& Brown, J. (2014). Electronic cigarettes: fact and faction. The British journal of general practice: the journal of the Royal College of General Practitioners, 64/626: 442-3. British Journal of General Practice. DOI: 10.3399/bjgp14X681253

White, H. (2008). Identity and Control: How Social Formations Emerge, 2nd ed. Princeton: Princeton University Press.

Whitehead, A. N. (1929). Process and Reality. An Essay in Cosmology. New York: Macmillan.

Woll, C. (2012). The brash and the soft-spoken: Lobbying styles in a transatlantic comparison. Interest Groups \& Advocacy, 1/2: 193-214. Nature Publishing Group. DOI: 10.1057/iga.2012.10

Woodruff, J. (2014). Appeal growing among kids, FDA cracks down on 'wild west' of ecigarettes. PBS Newshour. Retrieved May 29, 2015, from $<$ http://www.pbs.org/newshour/bb/appeal-growing-among-kids-fda-cracks-wild-west-ecigarettes/>

Wooten, M., \& Hoffman, A. J. (2008). Organizational Fields: Past, Present and Future. Greenwood R., Oliver C., Suddaby R., \& Sahlin K. (eds) The SAGE Handbook of Organizational Institutionalism, pp. 130-49. SAGE: Los Angeles, London, New Delhi \& Singapore. DOI: $10.4135 / 9781849200387$

World Health Organization. (2004). Effectiveness of sterile needle and syringe programming in reducing HIV/AIDS among injecting drug users. Geneva. Retrieved from <http://www.who.int/hiv/pub/prev_care/effectivenesssterileneedle.pdf>

- (2008a). Marketers of electronic cigarettes should halt unproved therapy claims. Media $\begin{array}{lllll}\text { Centre. } & \text { Retrieved } & \text { September 2015, from }\end{array}$ <http://www.who.int/mediacentre/news/releases/2008/pr34/en/> 
- (2008b). Transcript of WHO podcast - 26 September 2008. Media Centre. Retrieved $\begin{array}{llll}\text { September } & 2,2015, & \text { from }\end{array}$ <http://www.who.int/mediacentre/multimedia/podcasts/2008/transcript_48/en/>

- (2009). Report on the Scientific Basis for Tobacco Product Regulation. Copenhagen. Retrieved from <http://apps.who.int/iris/bitstream/10665/44213/1/9789241209557_eng.pdf>

—. (2010). Tobacco product regulation. WHO Drug Information, 24/1: 30-2.

- (2014). Electronic Nicotine Delivery Systems. Retrieved from <http://www.who.int/nmh/events/2014/backgrounder-e-cigarettes/en/>

—. (n.d.). Dependence Syndrome. Management of Substance Abuse. Retrieved September 9, 2015, from <http://www.who.int/substance_abuse/terminology/definition1/en/>

Wynne, B. (1996). May the Sheep Safely Graze? A Reflexive View of the Expert-Lay Knowledge Divide. Lash S., Szerszynski B., \& Wynne B. (eds) Risk, Environment and Modernity: Towards a New Ecology. SAGE Publications: London.

Yamin, C. K., Bitton, A., \& Bates, D. W. (2010). E-cigarettes: a rapidly growing Internet phenomenon. Annals of internal medicine, 153/9: 607-9. American College of Physicians. DOI: 10.7326/0003-4819-153-9-201011020-00011

Zhu, S.-H., Sun, J. Y., Bonnevie, E., Cummins, S. E., Gamst, A., Yin, L., \& Lee, M. (2014). Four hundred and sixty brands of e-cigarettes and counting: implications for product regulation. Tobacco Control, 23 Suppl 3/January: iii3-9. DOI: 10.1136/tobaccocontrol2014-051670

Table 1. Expectations and keys in the study of institutional change ${ }^{9}$

\begin{tabular}{|l|l|l|l|l|}
\hline Expectations & \multicolumn{3}{|c|}{ Types of key } & $\begin{array}{l}\text { Key parallels in the } \\
\text { relevant literature }\end{array}$ \\
\cline { 2 - 4 } & Signs & Symbols & Resources & \\
\hline
\end{tabular}

\footnotetext{
${ }^{9}$ Adapted from Vollmer 2013, p.55.
} 


\begin{tabular}{|l|l|l|l|l|}
\hline Normative & Sanctions & $\begin{array}{l}\text { Norms, customs, } \\
\text { morality }\end{array}$ & $\begin{array}{l}\text { Symbolic } \\
\text { capital }\end{array}$ & $\begin{array}{l}\text { Rhetorical strategies of } \\
\text { legitimacy (Suddaby \& } \\
\text { Greenwood 2005) } \\
\text { Normative and regulative } \\
\text { pillars (Scott 2008) }\end{array}$ \\
\hline Cognitive & Information & $\begin{array}{l}\text { Knowledge, } \\
\text { competence, } \\
\text { taste }\end{array}$ & $\begin{array}{l}\text { Cultural } \\
\text { capital }\end{array}$ & $\begin{array}{l}\text { Cultural-cognitive pillar } \\
\text { (Scott 2008) } \\
\text { Cognitive frames } \\
\text { (Beckert 2010) } \\
\text { Epistemic arbitrage } \\
\text { (Seabrooke 2014) } \\
\text { Sociology of expertise } \\
\text { (Eyal 2013) }\end{array}$ \\
& Positions & $\begin{array}{l}\text { Membership, } \\
\text { status, } \\
\text { reputation }\end{array}$ & Social capital & $\begin{array}{l}\text { Linked ecologies (Abbott } \\
\text { 2005) } \\
\text { Status networks (Podolny } \\
\text { 2005) } \\
\text { Social networks (Beckert } \\
\text { 2010) }\end{array}$ \\
\hline
\end{tabular}


Table 2. Characteristics of professionals interviewed ${ }^{10}$

\begin{tabular}{|c|c|c|c|c|}
\hline Interviewee & 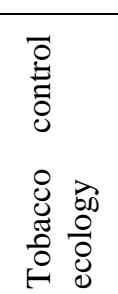 & 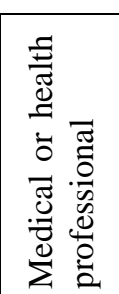 & 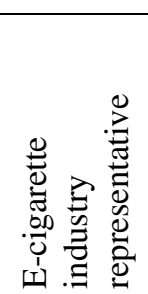 & Organizational affiliation \\
\hline 1 & $\mathrm{X}$ & & & Smoke Free Partnership \\
\hline 2 & $\bar{X}$ & & & Smoke Free Partnership \\
\hline 3 & & & & Greens/European Free Alliance \\
\hline 4 & $\mathrm{X}$ & & & European Respiratory Society \\
\hline 5 & & & & European People's Party \\
\hline 6 & & & & Alliance of Liberals and Democrats \\
\hline 7 & & & & Alliance of Liberals and Democrats \\
\hline 8 & & & $\mathrm{X}$ & Electronic Cigarette Industry Trade Association \\
\hline 9 & $\mathrm{X}$ & $\mathrm{X}$ & & Association of European Cancer Leagues \\
\hline 10 & & & & Independent consultant \\
\hline 11 & & & $\mathrm{X}$ & EPPA (Consultancy) \\
\hline 12 & & & $\mathrm{X}$ & EPPA (Consultancy) \\
\hline 13 & $\mathrm{X}$ & $\mathrm{X}$ & & German Cancer Research Institute \\
\hline 14 & & & & Swedish Match \\
\hline 15 & & & & Swedish Match \\
\hline 16 & & $\mathrm{X}$ & & Independent consultant \\
\hline 17 & & & $\mathrm{X}$ & Nicoventures \\
\hline 18 & & & $\mathrm{X}$ & Totally Wicked \\
\hline 19 & & & & European Smokeless Tobacco Council \\
\hline 20 & & & & European Smokeless Tobacco Council \\
\hline 21 & & & $\mathrm{X}$ & Tobacco Vapor Electronic Cigarette Association \\
\hline 22 & & & $\mathrm{X}$ & Vapourtrails.tv \\
\hline 23 & $\mathrm{X}$ & & & European Public Health Alliance \\
\hline 24 & & & & Independent consultant \\
\hline
\end{tabular}

${ }^{10}$ Inspired by Table 2 (p.8) in Seabrooke \& Tsingou 2014b. 
